\title{
ENDOSCOPIC STAPEDOTOMY- OUR EXPERIENCE
}

\author{
P. B. Kameswara Rao ${ }^{1}$, S. Ramesh ${ }^{2}$
}

1Associate Professor, Department of ENT, GEMS, Ragolu, Srikakulam, Andhra Pradesh, India.

${ }^{2}$ Assistant Professor, Department of ENT, RIMS, Srikakulam, Andhra Pradesh, India.

\section{BACKGROUND}

ABSTRACT

Otosclerosis is one of the commonest causes of non-suppurative conductive hearing loss. Small fenestra stapedotomy was first developed by Shea in 1962. After 50 years of first microscopic stapedotomy, endoscope-assisted stapedotomy was first described by Poe in 2000. Full endoscopic stapedotomy was performed by João Flávio Nogueira Júnior in 2008. There are few papers on endoscopic stapedotomy, so here we are doing a study of the endoscopic stapedotomy.

The aim of this study is to analyse whether Endoscopic Stapedotomy is safer and less traumatic.

\section{MATERIALS AND METHODS}

It is a descriptive study. There were 40 patients who underwent Endoscopic Stapedotomy for otosclerosis. Preoperative and postoperative pure tone averages and air-bone gaps were compared. Perioperative and postoperative complications were noted.

\section{RESULTS}

The surgeries were performed with endoscope and relevant anatomical structures were visualised without difficulty. Audiologic improvement was achieved in 37 of 40 patients. Postoperative air-bone gap was within $10 \mathrm{~dB}$ in 28 ears and between $10-20 \mathrm{~dB}$ in 9 ears. Unfortunately, sensorineural hearing loss was observed in 1 patient and vertigo in 5 patients.

\section{CONCLUSION}

Endoscopic stapes surgeries are technically feasible, safe and promising. In this series, the main advantages were virtually no trauma to the chorda tympani nerve and excellent visualisation of middle ear. The disadvantages were the lack of stereoscopic vision, having to work with one hand only and steep learning curve.

\section{KEY WORDS}

Endoscope, Otosclerosis, Stapedotomy, Chorda Tympani Nerve.

HOW TO CITE THIS ARTICLE: Rao PBK, Ramesh S. Endoscopic stapedotomy- our experience. J. Evolution Med. Dent. Sci. 2018;7(36):3954-3958, DOI: 10.14260/jemds/2018/884

\section{BACKGROUND}

Otosclerosis, which is one of the commonest causes of nonsuppurative conductive hearing loss. Valsalva was the first to describe otosclerosis in 1735, as ankylosis of the stapes to the margins of the oval window. ${ }^{1}$

Otospongiotic foci are common on walls of oval window. The incidence of stapedial fixation is $1.8 \%$ in a population between 30 and 50 years. Cochlear and labyrinthine otosclerosis causing sensorineural type of hearing loss is due to otospongiotic foci in labyrinthine capsule or due to enzymatic impairment in membranous cochlea.

The technique of surgery for otosclerosis has evolved in the hands of different surgeons and there is diversity of opinion among the otologists about the type of operations that will give satisfactory and lasting results. In this effort, new modifications have been introduced from time to time.

In 1876 at the University of Graz, Austria the first mobilisation surgery was done for stapes fixation. First stapedectomy was done by Jack of Boston in 1891. In 1897, Passow performed the first fenestration of promontory.

'Financial or Other Competing Interest': None.

Submission 10-08-2018, Peer Review 25-08-2018,

Acceptance 27-08-2018, Published 03-09-2018.

Corresponding Author:

Dr. S. Ramesh,

Assistant Professor, Department of ENT,

RIMS, Srikakulam-532001,

Andhra Pradesh, India.

E-mail: rameshseepana@rediffmail.com

DOI: $10.14260 /$ jemds $/ 2018 / 884$

\section{(c) $($ ) $\$$}

Lempert performed the fenestration surgery in 1938. Rosen performed mobilisation in 1952. Modern stapes surgery started after John Shea performed his first surgery in 1958, which showed promising results.

Small fenestra stapedotomy was first developed by Shea in 1962.2

After 50 years of first Microscopic stapedotomy, Endoscope-assisted stapedotomy was first described by Poe in 2000.3 Fully endoscopic stapedotomy performed by João Flávio Nogueira Júnior, in 2008.4

\section{New Developments}

Stapedotomy with stapedial tendon preservation, in which stapedial tendon is not cut and the stapedial suprastructure with the preserved muscle tendon was transpositioned onto the longer arm of the incus and secured with a wire loop. Preserving the stapedius tendon can be done with laser. Patients having this tendon functioning have less intolerance to noise, hear better in noise and have less chance of damage to the inner ear from pressure changes.

\section{Laser Stapedotomy}

The laser stapedectomy is a procedure, which permits the surgeon to operate without touching the stapes. An opening is made in the frozen stapes footplate and prosthesis is inserted to allow sound waves to enter the inner ear, which restores the sound conducting mechanism and hearing. There is very little bleeding or scarring in this procedure and patient can go home several hours after surgery. 


\section{Laser STAMP (Laser Stapedotomy minus Prosthesis)}

In 1995, Dr. Silverstein developed a new technique called Laser STAMP. The laser is used to free the frozen stapes bone in patients with minimal otosclerosis, preserving most of the patient's normal stapes bone. This restores the patient's hearing without using a prosthesis. The advantages of preserving most of the patient stapes include reduced sensitivity to noise, decreased incidence of noise damage to the ear and reduced chances of trauma to the inner ear from changes in pressure flying or diving.

There are a few papers on endoscopic stapedotomy. 5 So here we are doing study of the endoscopic stapedotomy.

\section{Aim of the Study}

To study whether Endoscopic Stapedotomy is safer and less invasive.

\section{MATERIALS AND METHODS}

It is a descriptive study. 40 patients with otosclerosis were selected during January 2015 to January 2017 at Great Eastern Medical School, Ragolu, Srikakulam.

- $\quad$ All the patients underwent Endoscopic Stapedotomy.

- Performed by the same surgeon.

- Follow-up period ranged from 12 to 18 months.

\section{Selection Criteria}

- Progressive deafness of conductive type with onset in early adult life.

- Normal tympanic membrane.

- No other apparent cause of deafness.

- Pure tone audiogram.

- $\quad$ Air-bone gap $>25 \mathrm{db}$

- In Impedance

- As or A type tympanogram

- Absent acoustic reflex

\section{Exclusion Criteria to Surgery \\ Medically Unfit Patient}

- An only hearing ear that does well with amplification.

- Clinical evidence of labyrinthine hydrops.

- Pregnancy.

- Inner ear malformation.

- Poor cochlear reserve.

\section{Criteria of Success}

The success of operation was determined by the degree of closure of air-bone gap in speech frequencies (500, 1000 and $2000 \mathrm{db}$ ) and the results were classified into four categories. ${ }^{6}$

- Air-bone gap $10 \mathrm{db}$ or less - Excellent.

- Air-bone gap $11-20 \mathrm{db} \quad$ - Good.

- AB gap persisting at pre-operative - Poor level.

- Deterioration of hearing - Worse.

\section{The Surgical Technique Studied with Respect to}

- Extent of curetting the postero-superior bony external auditory canal.

- $\quad$ Time taken for surgery.

- Post-operative hearing results.

- Post-operative complications.

- Post-operative pain.

\section{Procedure}

All cases are done under local anaesthesia after premedication with pentazocine $1 \mathrm{cc}$ and promethazine $1 \mathrm{cc}$ intramuscular injection 30 minutes before surgery. The patients are positioned in supine position, the head turning away from surgeon.

Local infiltration was done with 1 in $1000001 \%$ lignocaine with adrenaline. Adrenaline (1: 2000)-soaked cottonoids are placed into the external auditory canal for 5 minutes after infiltration.

We are using $0^{\circ}$ and $30^{\circ} 3 \mathrm{~mm}$ diameter and $14 \mathrm{~cm}$ long endoscopes. $0^{0}, 30^{\circ}$ and $45^{\circ} 4 \mathrm{~mm}$ diameter, $18 \mathrm{~cm}$ long endoscope is also used when the external auditory canal is wide enough. We are using high definition camera systems and high definition monitors. Instruments are same as in traditional microscopic ear surgery are used. Light illumination is kept at optimal level to decrease the theoretical thermal injury to inner ear.

\section{Incision}

The classical Rosen's permeatal incision 6 to $8 \mathrm{~mm}$ away from annulus. With the advent of modern-day endoscopes there is wide angle and magnified view, which aides in better exposure of the operative field.

Flap elevation - tympanomeatal flap gently elevated with Rosen's knife towards the annulus. With a wide-angle view flap elevation is made easy, but trivial bleeding also may sometimes cause difficulty as technique is carried out with a single hand. This can be avoided by using adrenaline soaked cottonoids.

Exposure without curetting - after the flap elevation in microscopic stapedotomy, lot of postero-superior bony external meatal wall is curetted in order to visualise the suprastructure of stapes, foot plate and long process of incus. The major advantage with an endoscope is visualisation of stapes foot plate and suprastructure without any bony curetting.

The structures like horizontal part of facial nerve, base of pyramid and stapedial tendon are made out easily. Bony curetting is done to give effective manoeuvrability. Chorda tympani is not found to lie in the way of the endoscope, therefore there is a less chance of injury to it.

Stapes suprastructure removal: Stapedial tendon cutting with micro scissors.

While cutting stapedial tendon, little manoeuvrability is needed and necessary for more curved instruments arises. After cutting stapedial tendon, incudostapedial joint is dislocated with right angle prick. Stapes suprastructure is removed after controlled fracturing of posterior and anterior crura of stapes with right angle prick. The distance between long process of incus and foot plate is measured with measuring rod.

In our study, in most of the cases the distance between long process of incus and foot plate of stapes is $4 \mathrm{~mm}$. Creating controlled fenestra over foot plate of stapes by using a Skeeter Microdrill of $0.6 \mathrm{~mm}$ diameter diamond burr, making a controlled fenestra over foot plate of stapes in posterior $1 / 3$.

A Teflon piston prosthesis $(0.4 \mathrm{~mm}$ diameter $) 4.25 \mathrm{~mm}$ long (in most of the cases) was placed into this hole and fitted along the long process of the incus. Soft tissue seal was done with Gelfoam and ear lobule fat. The tympanomeatal flap was 
repositioned, and the external auditory canal was filled with Gelfoam.

Post-operatively, all the patients are instructed to avoid swimming and exposure to noise. All are advised to report for review after 1 month and then every 3 months. Postoperative audiometry was done after 1 month and 3 months.

\section{RESULTS}

The present series consists of a study of 40 otosclerotic ears, which were subjected to endoscopic stapedotomy. The observation and inferences were drawn as a result of the study discussed below.

\section{Age}

In our study we observed that between 21 - 30 years 20 patients, between 31 - 40 years 16 patients, between 41 - 50 years 4 patients. The disease is mostly seen in 2 nd and $3 \mathrm{rd}$ decades. Out of the 40 cases studied, 36 cases are in this age group.

\begin{tabular}{|c|c|}
\hline Age Distribution No. of Cases & [In Years] \\
\hline $21-30$ & 20 \\
\hline $31-40$ & 16 \\
\hline $41-50$ & 04 \\
\hline 51 and Above & 00 \\
\hline
\end{tabular}

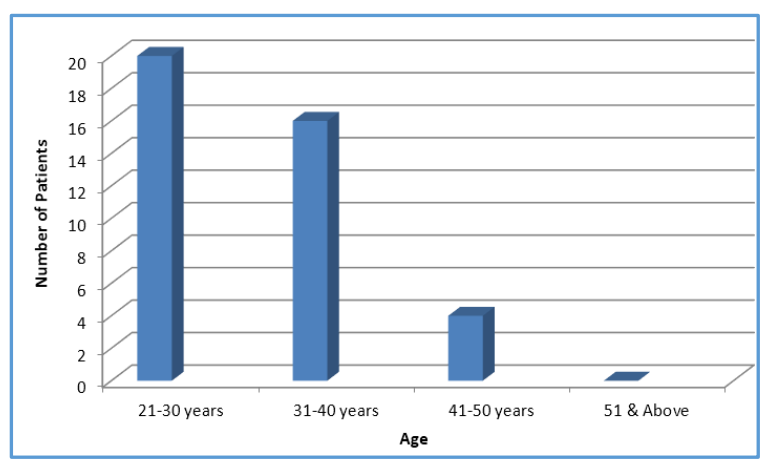

\section{Sex Distribution}

Females were found to be somewhat dominating over males. Of the 40 cases studied, 22 were females and 18 were males.

\begin{tabular}{|c|c|}
\hline Sex & No. of Cases \\
\hline Male & 18 \\
\hline Female & 22 \\
\hline Total & $\mathbf{4 0}$ \\
\hline
\end{tabular}

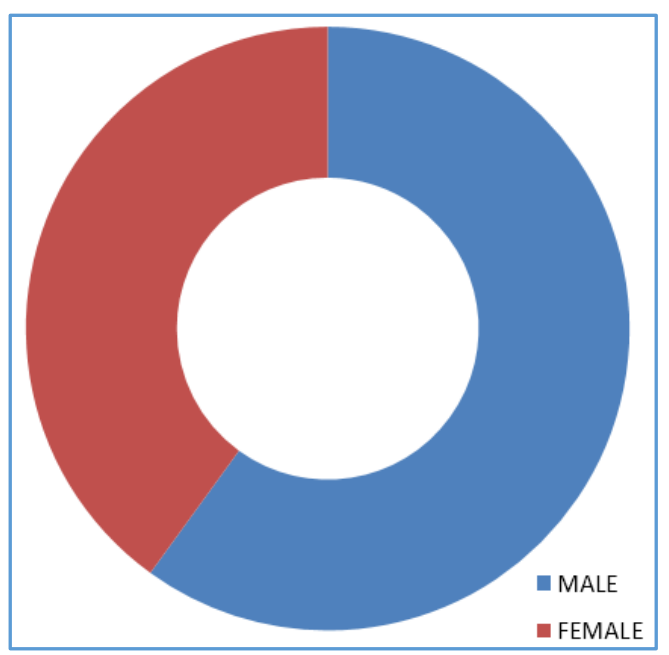

\section{Pre-OP PTA}

26 number of the patients showed air-bone gap between 25$350 \mathrm{~dB}$ and 14 number of the patients showed air-bone gap between $36-45 \mathrm{~dB}$.

\begin{tabular}{|c|c|}
\hline Pre-OP AB GAP & Number of Cases \\
\hline $25-35 \mathrm{~dB}$ & 26 \\
\hline $36-45 \mathrm{~dB}$ & 14 \\
\hline
\end{tabular}

\section{Postoperative Air-Bone GAP}

28 number of patients showed closure of $a-b$ gap to within 10 dB. In 9 number of patients showed closure of a-b gap of 11 $20 \mathrm{~dB}$.

\begin{tabular}{|c|c|}
\hline Post-OP AB GAP & Number of Cases \\
\hline$<10 \mathrm{~dB}$ & 28 \\
\hline $11-20 \mathrm{~dB}$ & 09 \\
\hline$>21 \mathrm{~dB}$ & 03 \\
\hline
\end{tabular}

\begin{tabular}{|c|c|}
\hline Number of Complications in Endoscopic Stapedotomy & \\
\hline Vertigo & 5 \\
\hline Injury to Chorda Tympani & 0 \\
\hline SNHL & 1 \\
\hline Complications following Endoscopic Stapedotomy \\
\hline
\end{tabular}

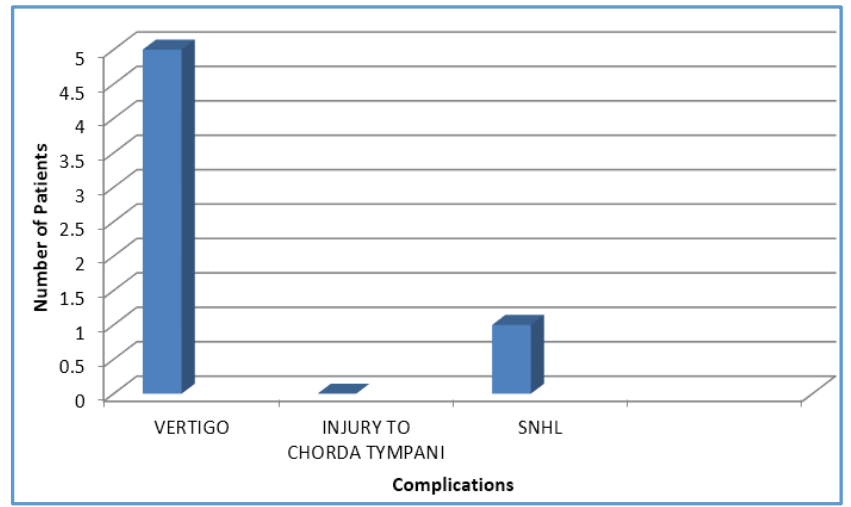

Labyrinthine damage causing vertigo occurred in 5 patients, which is transient, and all are free of symptoms after one to two weeks. No injury to chorda tympani was seen in our study. Sensorineural hearing loss was seen in one patient.

\begin{tabular}{|c|c|}
\hline Category & Number of Cases \\
\hline $\begin{array}{c}\text { Mild pain, not requiring } \\
\text { medication }\end{array}$ & 26 \\
\hline Pain requiring medication & 14 \\
\hline \multicolumn{2}{|c|}{ Postoperative Pain } \\
\hline
\end{tabular}

In our study 26 patients did not require any medication for pain postoperatively, only 14 patients required medication for pain postoperatively.

\section{Time Taken for Surgery}

Initial cases take longer operative time [55 - 75 mins], as number of cases are increasing it takes less time [45 - 60 mins]. 

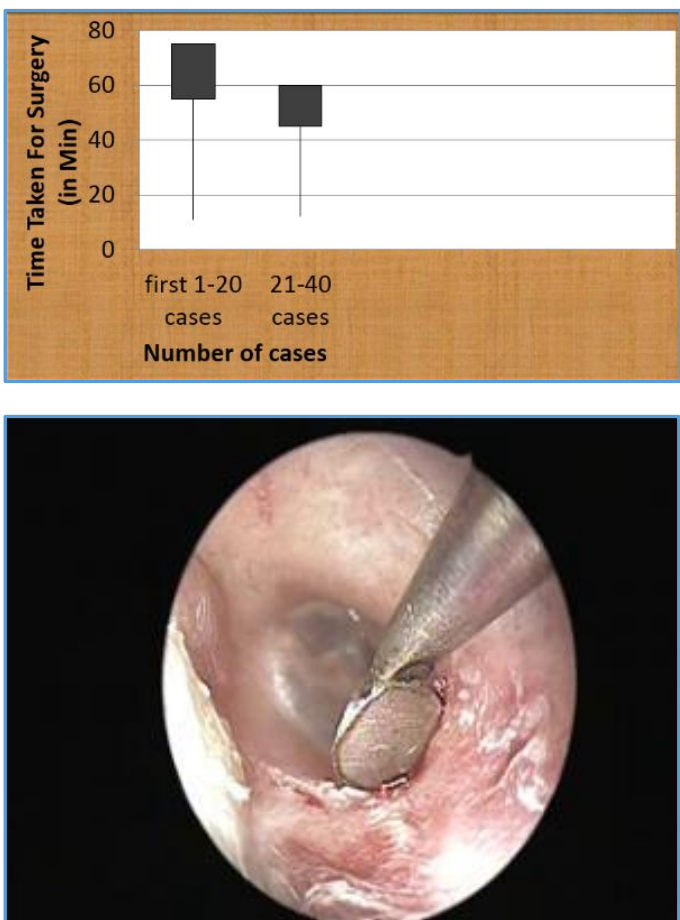

Figure 1. Incision: This Picture showing Canal Incision using a 0-degree endoscope with Rosen's Round Knife $6 \mathrm{~mm}$ away from the Annulus

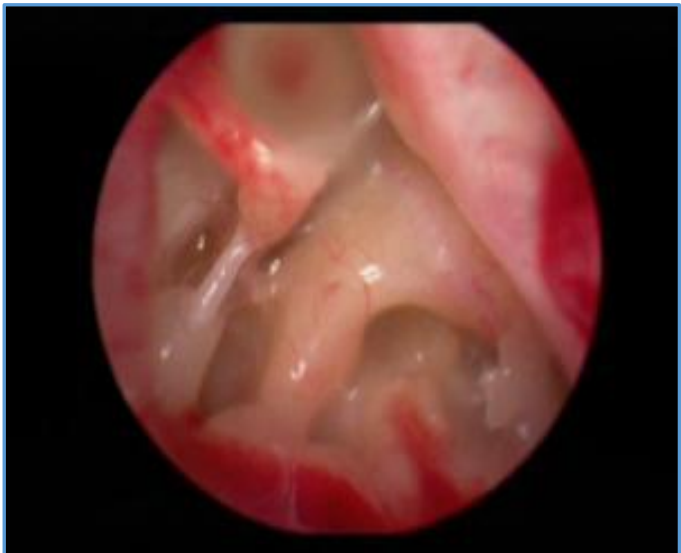

Figure 2. This Picture showing Wide Panoramic Endoscopic View without any bony curettage with 0 degree scope where we can see Base of Pyramid, Stapedial Tendon, Long Process of Incus, Posterior. This Wide Panoramic View is not possible to achieve with Microscope

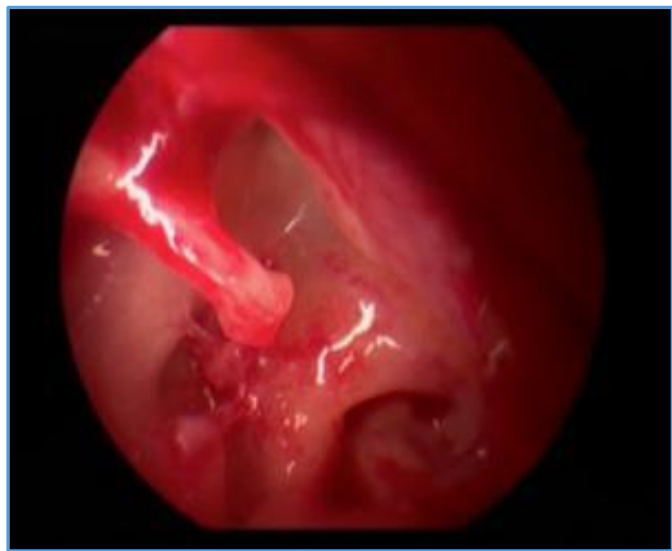

Figure 3. This Picture showing Foot Plate after removal of the Suprastructure before Fenestration with 0-degree Endoscope clearly demonstrating Overhanging Facial Nerve onto the Foot Plate

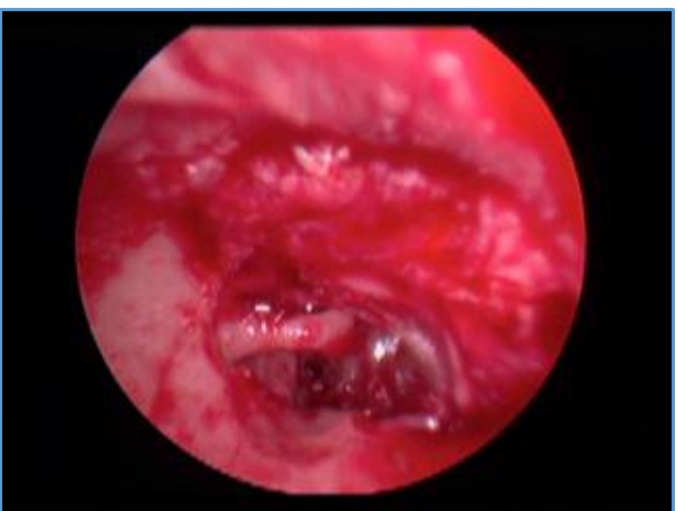

Figure 4. This Picture showing $0.6 \mathrm{~mm}$ Fenestration over the Footplate without any Perilymph Leak with 0-degree Endoscope

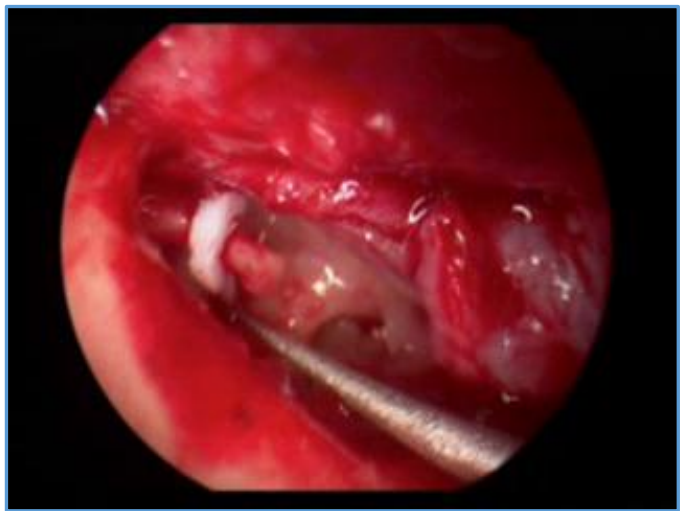

Figure 5. This Picture showing placement of $0.4 \mathrm{~mm}$ diameter $4.25 \mathrm{~mm}$ length Teflon Piston in the Fenestra with 0-degree Endoscope

\section{DISCUSSION}

This clinical series consists of a study of 40 otosclerotic patients who were subjected to endoscopic stapedotomy, their demographic information, clinical result and audiological evaluation are recorded and studied. Complications following endoscopic stapedectomy are also analysed. The disease is mainly observed in 2nd and 3rd decades. Out of the 40 cases studied, 36 cases are in this age group.

Females were found to be slightly dominating over males. Of the 40 cases studied, 22 were females and 18 were males. The patients presented with bilateral symptoms are more than unilateral symptoms. Comparison of studies for bilateral involvement with the other studies; in Glasscock study $72 \%$, Ginsberg et al 80\%; and in Levy et al study it was 66\%. 35\% of the patients presented with moderate hearing loss and $65 \%$ of the patients presented with moderately severe hearing loss. There are no patients with minimal or profound hearing loss. $65 \%$ of the patients showed air-bone gap between $25-35 \mathrm{~dB}$ and $35 \%$ of the patients showed air-bone gap between $36-45 \mathrm{~dB}$. The study showed as type of curve in $60 \%$ of the patients and A type of curve in $40 \%$ of the patients.

The main advantage of the operating microscope is giving a good magnified image in a straight line. It has some limitations in permeatal surgeries like stapedotomies, as the visual field becomes limited especially in tortuous narrow canals. However, it is still used worldwide in performing stapedotomies because of its satisfactory results. ${ }^{7}$ 
Endoscopes provide Wide Angle and Magnified View

Endoscopic procedure requires minimal bony curettage, hence less chance of injury to the chorda tympani. Endoscopic stapes surgery is preferred for patients with a narrow external ear canal. ${ }^{8}$

Endoscopic stapes surgery with postoperative hearing results are same as with microscopic stapes surgery results. In our study, large majority of the patients maintained the improvement in hearing pattern gained initially till the period of follow-up. $70 \%$ of the patients showed closure of a-b gap to within $10 \mathrm{~dB}$. 22.5\% of the patients showed closure of a-b gap of $11-20 \mathrm{~dB}$. In $7.5 \%$ of the patients, there is only slight improvement ( $>21 \mathrm{~dB}$ AB gap closure).

Surgical field should bleed less to have a good view, minimal bleed also causes difficulty in proceeding with stapes surgery.

\section{Complications following Endoscopic Stapedotomy}

Most of the complications associated with stapedotomy typically result from either cochlear or labyrinthine trauma. As manifested by elevated pure tone thresholds and reduced speech discrimination scores, cochlear trauma leads to sensorineural hearing loss in less than $2 \%$ of patients. Labyrinthine damage causing vertigo occurs in approximately $2 \%$ of patients.

\section{Vertigo}

Vestibular reactions are due to irritation of the labyrinth and appear in the form of nausea, vomiting, unsteadiness of gait and nystagmus. They are usually mild and last for 2 - 3 days. In the present study 3 patients had such disturbance and subsided within 2 to 3 days, 2 cases subsided within one week. Infection is hardly seen after stapes operation performed under careful aseptic technique.

\section{Sensorineural Hearing Loss [SNHL]}

The most devastating complication of stapes surgery is sensorineural hearing loss, which occurs in less than $2 \%$ of cases. Sensorineural hearing loss may be mild or isolated to high frequencies. When sensorineural hearing loss is suspected, prednisone is started immediately and tapered. In our study, one case had SNHL.

In endoscopic stapes surgery, post-operative pain is minimal. In our study 26 patients did not require any medication for pain postoperatively, only 14 patients required medication for pain postoperatively. Initial cases take longer operative time [55 - 75 mins], as number of cases are increasing it takes less time [45- 60 mins].

It is easy to visualise, but minimal curettage is needed to manoeuvre in endoscopic stapedotomy.

\section{Disadvantages of Endoscopic Procedure ${ }^{9}$}

1. Lack of a depth perception. As the endoscopic view is stereoscopic, there is lack of depth perception which is overcome with experience and training.

2. Inability to work with two hands. As the surgeon holds the endoscope with one hand, the endoscopic stapes surgery is one handed. Hence, there is an inability to work with two hands.
3. Theoretical disadvantage of the endoscopic technique is the possibility of hearing loss due to thermal injury to inner ear resulting in sensorineural hearing loss. This can be overcome by frequent charge of endoscopes $0^{0}$, $30^{\circ}, 45^{\circ}$ and keeping the light at optimal settings and keeping the endoscope sufficiently away from the tissue.

4. Significant burden of learning. Since endoscopic ear surgery needs meticulous handling, there is burden of learning. This can be overcome by starting endoscopic ear surgery early in career during residency programme.

5. In endoscopic stapedotomy the range of movements of instruments were restricted because of presence of endoscope in external auditory canal, which can be overcome with development of more curved instruments and using lower diameter endoscopes like $3 \mathrm{~mm}$ and 2.7 $\mathrm{mm}$ whenever possible.

\section{CONCLUSION}

Postoperative hearing results are as good as in microscopic surgery.

1. As bony curetting is minimal in endoscopic stapedotomy, injury to chorda tympani is less with minimal postoperative pain.

2. Endoscopic stapedotomy if not superior to microscopic stapedotomy, it is as good as microscopic stapedotomy and a great tool to demonstrate for the residents.

3. As there is lack of a stereoscopic view in endoscopic stapedotomy, it is better to perform initial stapedotomy surgeries with microscope, as experience increases can shift to endoscope.

\section{REFERENCES}

[1] Makarem AO, Hoang TA, Lo WW, et al. Cavitating otosclerosis: clinical, radiologic and histopathologic correlations. Otol Neurotol 2010;31(3):381-4.

[2] Shea JJ Jr. Fenestration of the oval window. Ann Otol Rhinol Laryngol 1958;67(4):932-51.

[3] Poe DS. Laser-assisted endoscopic stapedectomy: a prospective study. Laryngoscope 2000;110(5 Pt 2 Suppl 95):1-37.

[4] Migirov L, Wolf M. Endoscopic transcanal stapedotomy: How I do it? Eur Arch Otorhinolaryngol 2013;270(4):1547-9.

[5] Özdek A, Bayir Ö, Keseroğlu K, et al. Fully endoscopic stapes surgery: preliminary results. Ann Otolaryngol Rhinol 2016;3(1):1085.

[6] Thamjarayakul T, Supiyaphun P, Snidvongs K. Stapes fixation surgery: stapedectomy versus stapedotomy. Asian Biomedicine 2010;4(3):429-34.

[7] Moneir W, Abd El-fattah AM, Mahmoud E, et al. Endoscopic stapedotomy: the merits and demerits. Ann Clin Otolaryngol 2016;1(1):1001.

[8] Kojima H, Komori M, Chikazawa S, et al. Comparison between endoscopic and microscopic stapes surgery. Laryngoscope 2014;124(1):266-71.

[9] Nogueira Júnior JF, Martins MJ, Aguiar CV, et al. Fully endoscopic stapes surgery (stapedotomy): technique and preliminary results. Braz J Otorhinolaryngol 2011;77(6):721-7. 